DOI: 10.12731/2227-930X-2021-11-4-31-42 УДК 629.113

\title{
НЕСТАЦИОНАРНЫЕ ХАРАКТЕРИСТИКИ БОКОВОГО УВОДА ЛЕГКОВЫХ ФРИКЦИОННЫХ ШИН НА ЗИМНЕЙ ДОРОГЕ, ПОКРЫТОЙ ПЕСЧАНО-СОЛЯНОЙ СМЕСЬЮ
}

\section{Гергенов С.М.}

Устойчивость движения автотранспортных средств в холодное время года обеспечивается способностью автомобильныхх шин $\kappa$ созданию боковых реакиий на зимних дорогах. Боковое сиепление шины с опорной поверхностью оценивается ее характеристиками бокового увода, по которым определяют коэффициент бокового сиепления и критический угол увода шины. С применением химических противогололедных материалов существенно ухудшились сиепные свойства шин, особенно, в боковом направлении. Отсутствие знаний о процессах движения шины с боковым уводом на зимней дороге, покрытой химическими противогололедными материалами определяет актуальность научного исследования.

В статье рассматриваются нестаиионарные характеристики бокового увода легковых фрикиионных шин Amtel NordMaster 175/70R13, полученные по результатам их испытаний на зимней дороге общего пользования, покрытой укатанным снегом и песчано-соляной смесью. Графики показывают, что применение хлорида натрия снижает боковое сцепление фрикиионных шин и устойчивость движения автотранспортных средств.

Цель - получение нестационарных характеристик бокового увода легковых фрикиионных шин на дороге, покрытой укатанным снегом и песчано-соляной смесью, и оценочных параметров бокового сиепления.

Метод или методология проведения работы: дорожный метод испытаний с использованием разработанных автором методики и шинного тестера для исследования нестационарного бокового увода автомобильных шин. 
Результаты: получены нестационарные характеристики бокового увода легковых фрикиионных шин Amtel NordMaster 175/70R13, определены коэффициенты бокового сиепления и критические угль увода.

Область применения результатов: полученные результаты необходимы для корректировки математической модели, позволяющей выполнять аналитическое исследование процессов бокового увода автомобильных шин на дорогах, имеющих зимнюю скользкость.

Ключевые слова: песчано-соляная смесь; боковой увод; коэффициент бокового сиепления

\section{THEORETICAL APPROACHES TO RESEARCH THE ROLLING PROCESS OF THE DRIVEN WHEEL SIDE DRAWER ON A WINTER ROAD}

\section{Gergenov S.M.}

The stability of the movement of motor vehicles in the cold season is ensured by the ability of car tires to create lateral reactions on winter roads. The lateral adhesion of the tire to the support surface is evaluated by its lateral withdrawal characteristics, which determine the coefficient of lateral adhesion and the critical angle of the tire withdrawal. With the use of chemical deicing materials, the coupling properties of tires have significantly deteriorated, especially in the lateral direction. The lack of knowledge about the processes of movement of a tire with lateral withdrawal on a winter road covered with chemical deicing materials determines the relevance of scientific research.

The article discusses the non-stationary characteristics of the lateral withdrawal of Amtel NordMaster175/70R13 passenger friction tires, obtained from the results of their tests on a winter public road covered with rolled snow and sand-salt mixture. The graphs show that the use of sodium chloride reduces the lateral grip of friction tires and the stability of motor vehicles. 
Purpose - obtaining non-stationary characteristics of lateral withdrawal of passenger friction tires on a road covered with rolled snow and sand-salt mixture, and estimated parameters of lateral traction.

Methodology: a road test method using the methodology and tire tester developed by the author to study the unsteady lateral withdrawal of automobile tires.

Results: The unsteady characteristics of the lateral withdrawal of Amtel NordMaster 175/70R13 passenger friction tires were obtained, the coefficients of lateral adhesion and critical withdrawal angles were determined.

Practical implications: the obtained results are necessary to correct the mathematical model that allows performing an analytical study of the processes of lateral withdrawal of automobile tires on roads with winter slipperiness.

Keywords: sand-salt mixture; lateral withdrawal; coefficient of lateral adhesion

В холодное время года на автомобильных дорогах образуется зимняя скользкость, связанная с появлением снежно-ледяных отложений (СЛО) в виде рыхлого снега, снежного наката и стекловидного льда. На таких СЛО коэффициент сцепления шин снижается до значений 0.25-0.08 [9], при которых предельные по сцеплению значения боковых реакций недостаточны для предотвращения бокового скольжения (заноса) колеса [10]. Для ликвидации СЛО в Российской Федерации широкое применение получил комбинированный способ борьбы с зимней скользкостью с использованием смеси фрикционного противогололедного материала (песок, золошлаковые отходы и др.) и химического противогололедного реагента (хлорид натрия) [4]. Как показали исследования [3] применение такого комбинированного противогололедного материала (ПГМ) приводит к появлению на зимней дороге многослойного покрытия, т.н. дорожного «сэндвича», на котором любые шины покрываются грязевым слоем, скользят по другим слоям и теряют способность к созданию боковых и про- 
дольных реакций. Обзор открытых научных источников показывает, что есть значительный научный задел, сформированный учеными МАДИ, НАМИ, СибАДИ и др., в исследовании продольного сцепления шины с дорогой в тормозном режиме движения колеса с применением различных шинных тестеров [8]. По исследованию бокового сцепления шин на опорных поверхностях с низким сцеплением известны работы $[6,7]$ по определению характеристик и параметров бокового увода шин на опорной поверхности бегового барабана с ледяным покрытием. Полученные в стендовых условиях выходные характеристики шин и оценочные параметры бокового сцепления не отражают в полной мере особенности движения автомобильных колес при действии боковой силы на зимних дорогах в реальных условиях эксплуатации. Кроме того, не учитывается влияние химических противогололедных реагентов на сцепные свойства шин. В МАДИ совместно с НАМИ ведутся исследования сцепных характеристик шипованных шин, рассчитываемых по предельным параметрам устойчивости движения шинного тестера, сделанного на базе автомобиля, на повороте в режиме экстренного торможения, определяемых в специальных зимних условиях автополигона [11] .

Известен ряд зарубежных исследований, связанных с оценками влияния зимней дорожной скользкости на сцепные свойства шин. В работе [13] отражены экспериментальные исследования по измерению продольных и поперечных характеристик шин при прохождении поворотов и торможении на дорогах, покрытых смесью снега и воды или смесью льда и воды В исследовании [14] выполнялась оценка влияния льда и снега на коэффициент поперечного трения шины с дорогой. Эксперименты выполнялись в различных дорожных условиях: голый сухой, сухой с участками льда, гололед и тремя уровнями накопления снега. В работе [15] приведены результаты испытаний шин на поперечное, так и на продольное сцепление на зимних покрытиях. В статье [12] приведены результаты испытаний шин на льду, уплотненном снегу и дезагрегированном снегу. Установлено, что для уплотненных и дезагрегированных 
снежных поверхностей боковой коэффициент трения приближается к максимальному значению с увеличением угла скольжения приблизительно до 15 градусов. Для льда максимальный боковой коэффициент трения достигается при малых углах скольжения, обычно 2-4 градуса. Однако, в вышеперечисленных работах не рассмотрено влияние химических противогололедных реагентов на сцепные свойства шин при действии боковых сил. Отсутствие знаний о процессе взаимодействия эластичной шины с поверхностью дороги, покрытой СЛО и химическими противогололедными реагентами, при качении колеса с боковым уводом, определяет необходимость проведения научного исследования.

Сложность и многофакторность процессов, протекающих в пятне контакта эластичной шины автомобильного колеса при движении с боковым уводом по опорной поверхности зимней дороги, не позволяет выполнить их аналитическое исследование без проведения дорожных экспериментов. На основе разработанной методики [2] и модернизированного шинного тестера [3] автором было выполнено экспериментальное исследование нестационарного бокового увода фрикционных шин Amtel NordMaster 175/70R13 82Q (рисунок 1) с различным износом протектора на горизонтальном участке дороги общего пользования, покрытой укатанным снегом и песчано-соляной смесью.

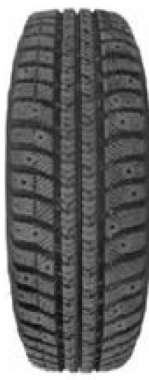

a)

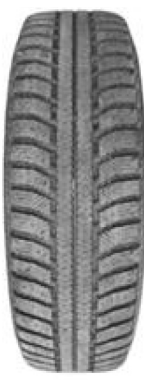

б)

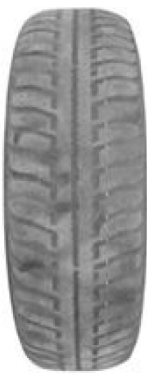

в)

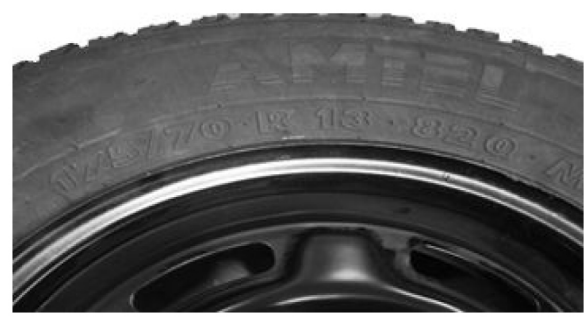

Рис. 1. Легковые фрикционные шины Amtel NordMaster 175/70R13 82Q с износом беговой дорожки протектора

а) $0 \%$ б) $45 \%$ в) $89 \%$ 
В процессе дорожных экспериментов измерялись боковые и нормальные реакции в пятнах контактов испытываемых шин с опорной поверхностью дороги, углы бокового увода при повороте колес шинного тестера с постоянной угловой скоростью 0,052(3) рад/с в диапазоне от $0^{\circ}$ до $30^{\circ}$. Циклы экспериментов повторялись при изменении скорости движения в интервале 5-30 км/ч и нормальной нагрузки на колеса шинного тестера 3500 и 4040 Н. Давление воздуха в шинах поддерживалась равной 0,2 МПа.

После обработки результатов экспериментов по их средним значениям построены графики нестационарных характеристик бокового увода испытываемых шин в виде зависимостей коэффициентов боковой силы $\left(\mathrm{R}_{\mathrm{y}} / \mathrm{R}_{\mathrm{z}}\right)$ от угла бокового увода $(\mathrm{d})$, часть из которых представлена на рисунках 2-5. Графики показывают, что для всех испытываемых шин на дороге, покрытой укатанным снегом и ПСС, коэффициенты бокового сцепления достигают предельных значений 0.2 при критических углах увода не более 2 градусов.
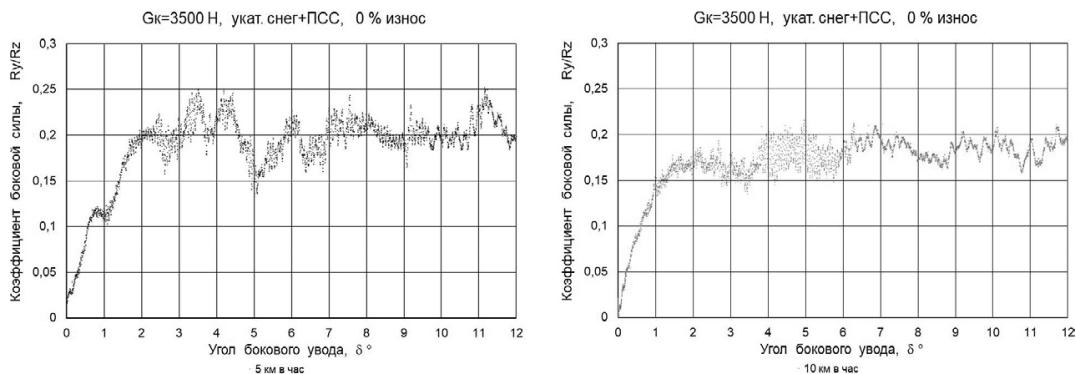

$\mathrm{GK}=3500 \mathrm{H}$, укат. $\mathrm{cHer}+\Pi \mathrm{CC}, 0 \%$ износ
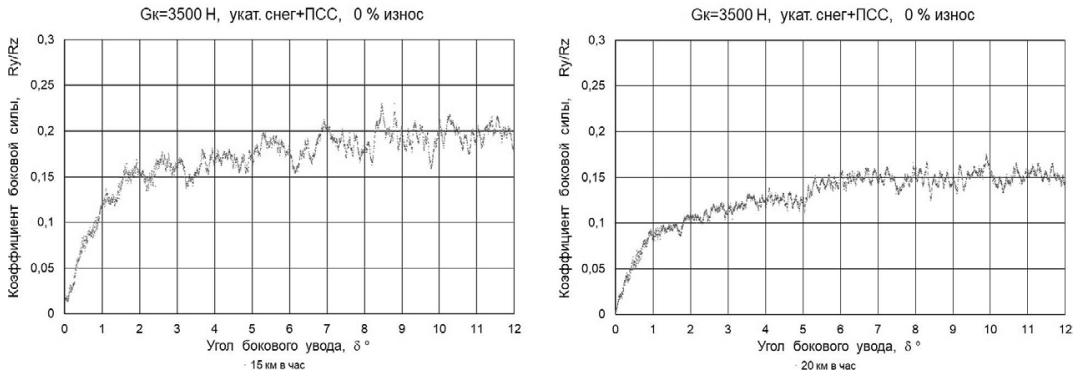

Рис. 2. Нестационарные характеристики бокового увода новой фрикционной шины Amtel NordMaster 175/70R13, $\mathrm{G}_{\mathrm{\kappa}}=3500 \mathrm{H}$ 

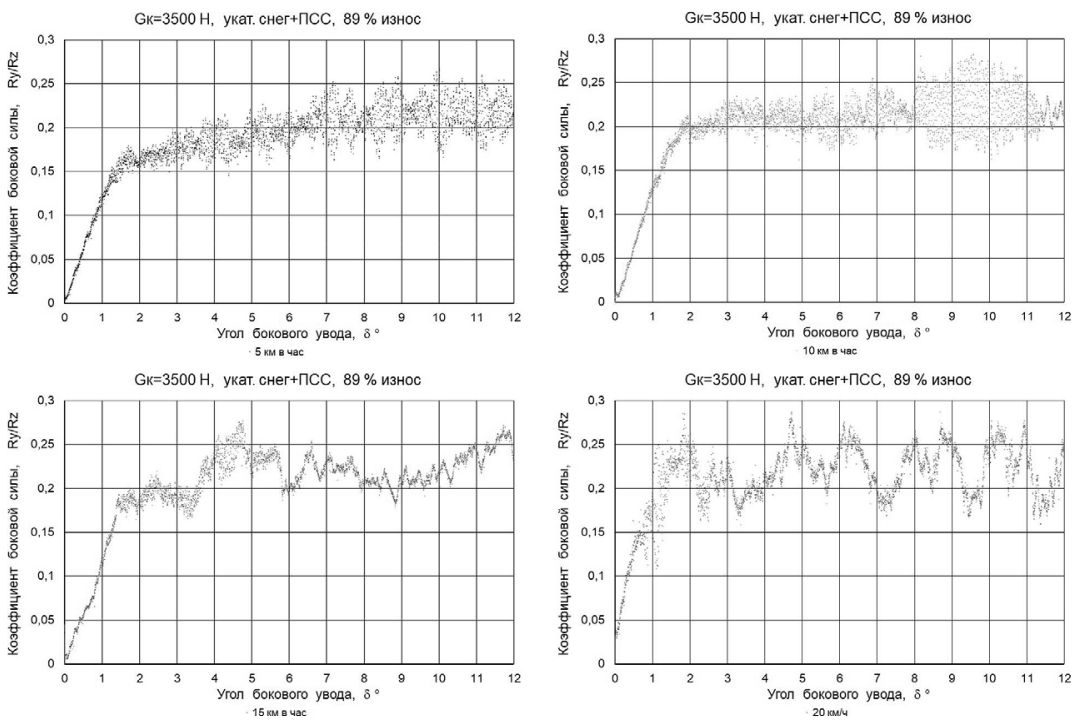

Рис. 3. Нестационарные характеристики бокового увода фрикционной шины Amtel NordMaster 175/70R13, $\mathrm{G}_{\mathrm{\kappa}}=3500$ H, износ 89\%
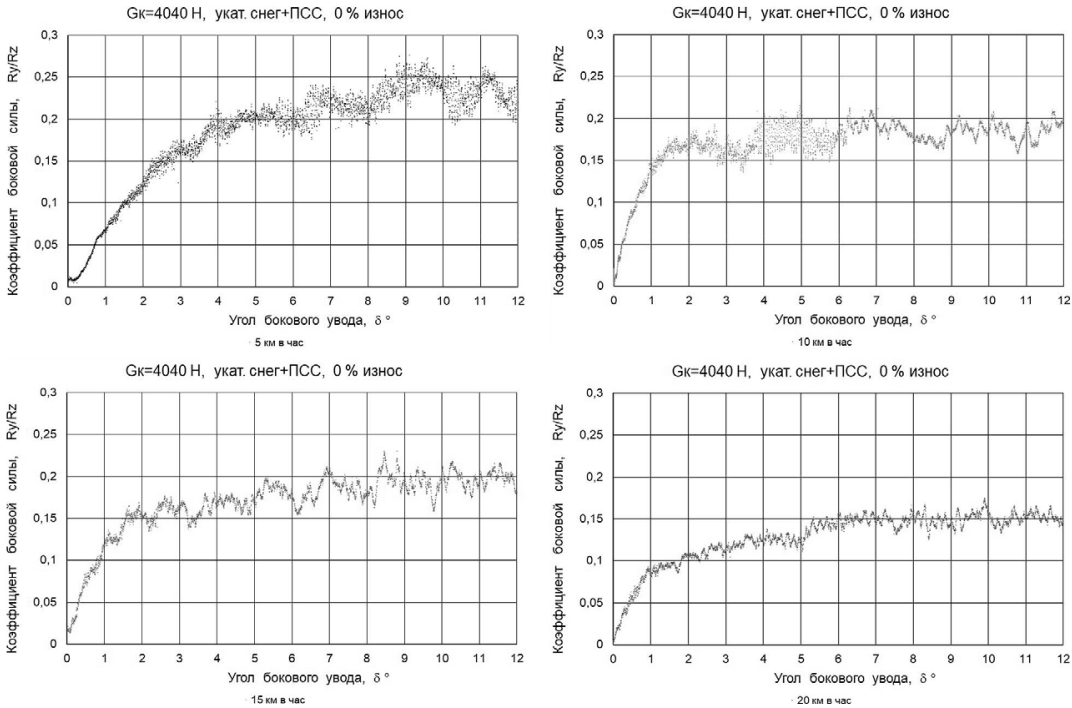

Рис. 4. Нестационарные характеристики бокового увода новой фрикционной шины Amtel NordMaster 175/70R13, $\mathrm{G}_{\mathrm{\kappa}}=4040 \mathrm{H}$ 

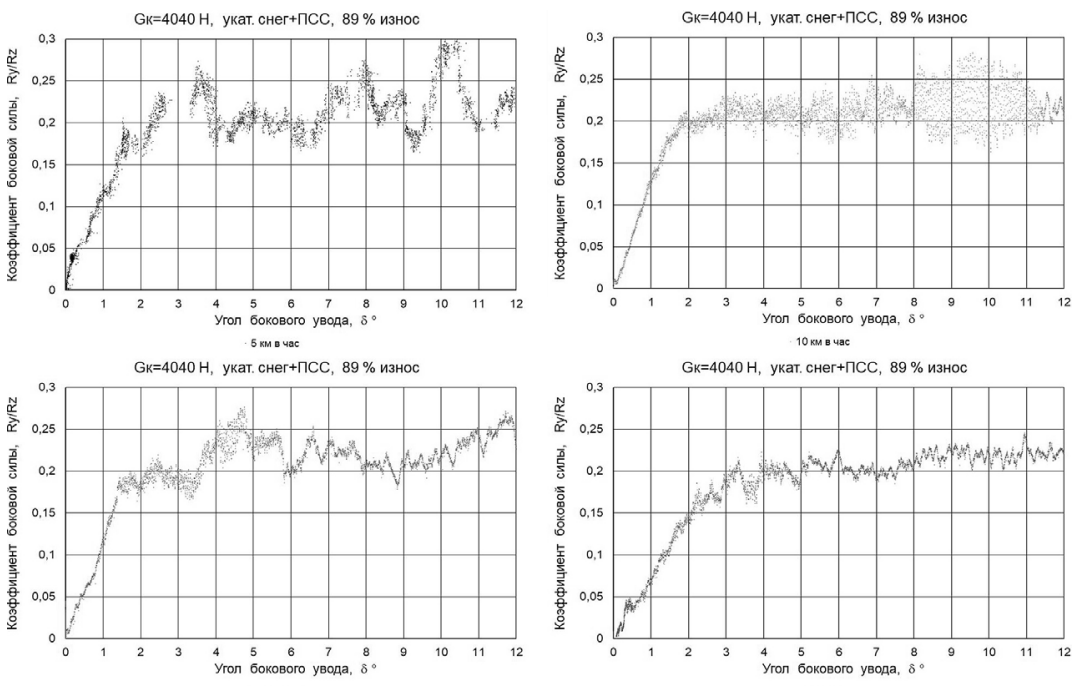

Рис. 5. Нестационарные характеристики бокового увода фрикционной шины Amtel NordMaster 175/70R13, $\mathrm{G}_{\mathrm{\kappa}}=4040$ H, износ 89\%

При увеличении скорости движения от 5 до 20 км/ч коэффициент бокового сцепления еще снижается с 0.2 до 0.1. Изменение нормальной нагрузки на колесо не оказывает существенного влияния на боковое сцепление шин. При увеличении углов бокового увода больше критических значений боковое скольжение шин сопровождается колебательными процессами срыва пятна контакта шины с опорной поверхностью дороги.

Таким образом, можно сделать вывод о том, что применение химического противогололедного реагента (хлорида натрия) в составе комбинированного ПГМ снижает способность шины к созданию боковой реакции, что негативно влияет на устойчивость движения автотранспортного средства.

Исследование было профинансировано Восточно-Сибирским государственным университетом технологий и управления и выполнено в рамках гранта «Молодые ученые ВСГУТУ 2021» (Приказ № 435od om 10.03.2021). 


\section{Сиисок литературы}

1. Гергенов С.М. О влиянии химических противогололедных материалов на движение и эксплуатационные свойства колёсных транспортных средств (в качестве обсуждения) / Федотов А.И., Гергенов С.М. // Журнал автомобильных инженеров. 2015. № 2 (91). C. 20-23.

2. Гергенов С.М. Методика определения характеристик нестационарного бокового увода шин в дорожных условиях // Безопасность колесных транспортных средств в условиях эксплуатации: сборник материалов 110-й Международной научно-технической конференции / Под редакцией А.И. Федотова. Иркутск, 2021. С. 223 -228.

3. Гергенов С.М. Модернизация шинного тестера для исследования нестационарного бокового увода шин в дорожных условиях // Безопасность колесных транспортных средств в условиях эксплуатации: сборник материалов 110-й Международной научно-технической конференции / Под редакцией А.И. Федотова. Иркутск, 2021. C. 96-101.

4. ГОСТ 33387-2015. Дороги общего пользования. Противогололедные материалы. Технические требования.

5. Иванов А.М., Кристальный С.Р., Попов Н.В., Фомичев В.А. Определение сцепных характеристик шипованных шин с уводом // Журнал автомобильных инженеров. 2017. № 6 (107). С. 14-21.

6. Капралов С.С. Испытания шин на барабанном стенде с ледяным покрытием /С.С. Капралов, П.Н. Малюгин, А.М. Зарщиков, В.А. Ковригин // Автомобильная промышленность. 2003. № 3. С. 28-29.

7. Ковригин В.А. Методы и результаты испытаний шин на льду в стендовых условиях // Межвузовский сборник трудов молодых ученых, аспирантов и студентов. Омск: СибАДИ, 2004. Вып. 1, Ч. 1. C. $84-88$.

8. Никульников Э.Н. Шинные тестеры - инструмент метрологической аттестации испытательных участков дорожных поверхностей с различными коэффициентами сцепления / Э.Н. Никульников, А.А. Барашков, А.А. Логунов // Автомобильная промышленность. 2011. № 6. C. 34-38. 
9. Руководство по борьбе с зимней скользкостью на автомобильных дорогах. Утверждено распоряжением Минтранса России от 16.06.2003 № OC-548-p.

10. Теория автомобиля. Учебник для вузов / В.Н. Кравец, В.В. Селифонов. М.: ООО «Гринлайт+», 2011. 884 с.

11. Шинный тестер для исследования характеристик шипованных шин. С.Р. Кристальный, В.Н. Задорнов, Н.В. Попов, В.А. Фомичев, А.А. Шляхтин // Вестник МАДИ. 2013. Вып. 3 (34). С.11-18.

12. Phetteplace G., Shoop S., Slagle T. Measuring lateral tire performance on winter surfaces // Tire Science and Technology. 2007. Vol. 35(1). P. 56-68.

13. Ruzinskas Andrius, Giessler Martin, Gauterin Frank. Experimental in-vestigation of tire performance on slush // Eksploatacja i niezawodnosc - mainte-nance and reliability. 2021. Vol. 23(1). P. 103-109.

14. Salimi Sahar, Nassiri Somayeh, Bayat Alireza. Lateral coefficient of friction for characterizing winter road conditions // Canadian journal of civil engi-neering. 2016. Vol. 43(1). P. 73-78.

15. Shoop S.A., Kestler M., Wieder W.L., MacDonald K. Lateral and Longitudinal Traction Measurements on Unpaved and Winter Road Surfaces // 18th International Conference of the International Society for Terrain Vehicle Systems 2014. Seoul, Korea, 2014. P. 64.

\section{References}

1. Fedotov A.I., Gergenov S.M. Zhurnal avtomobil'nykh inzhenerov, 2015, no. 2 (91), pp. 20-23.

2. Gergenov S.M. Bezopasnost'kolesnykh transportnykh sredstv v usloviyakh ekspluatatsii: sbornik materialov 110-y Mezhdunarodnoy nauchno-tekhnicheskoy konferentsii [Safety of wheeled vehicles in operating conditions: collection of materials of the 110th International Scientific and Technical Conference] / Edited by A.I. Fedotov. Irkutsk, 2021, pp. 223-228.

3. Gergenov S.M. Bezopasnost 'kolesnykh transportnykh sredstv v usloviyakh ekspluatatsii: sbornik materialov 110-y Mezhdunarodnoy nauchno-tekhnicheskoy konferentsii [Safety of wheeled vehicles in operating conditions: 
collection of materials of the 110th International Scientific and Technical Conference] / Edited by A.I. Fedotov. Irkutsk, 2021, pp. 96-101.

4. GOST 33387-2015. Public roads. Anti-icing materials. Technical requirements.

5. Ivanov A.M., Kristal'nyy S.R., Popov N.V., Fomichev V.A. Zhurnal avtomobil'nykh inzhenerov, 2017, no. 6 (107), pp. 14-21.

6. Kapralov S.S., Malyugin P.N., Zarshchikov A.M., Kovrigin V.A. Avtomobil'naya promyshlennost', 2003, no. 3, pp. 28-29.

7. Kovrigin V.A. Mezhvuzovskiy sbornik trudov molodykh uchenykh, aspi-rantov $i$ studentov [Interuniversity collection of works of young scientists, graduate students and students]. Omsk: SibADI, 2004. Issue 1, part 1, pp. 84-88.

8. Nikul'nikov E.N., Barashkov A.A., Logunov A.A. Avtomobil'naya promyshlennost', 2011, no. 6, pp. 34-38.

9. Guidelines for combating winter slipperiness on roads. Approved by order of the Ministry of Transport of Russia dated June 16, 2003 No. OS-548-r.

10. Kravets V.N., Selifonov V.V. Teoriya avtomobilya. Uchebnik dlya vuzov [Car theory. Textbook for universities]. M.: OOO «Grinlayt+», 2011, 884 p.

11. Kristal'nyy S.R., Zadornov V.N., Popovv N.V., Fomichev V.A., Shlyakhtin A.A. Vestnik MADI, 2013, no. 3 (34), pp.11-18.

12. Phetteplace G., Shoop S., Slagle T. Measuring lateral tire performance on winter surfaces. Tire Science and Technology, 2007, vol. 35(1), pp. 56-68.

13. Ruzinskas Andrius, Giessler Martin, Gauterin Frank. Experimental investigation of tire performance on slush. Eksploatacja i niezawodnosc - maintenance and reliability, 2021, vol. 23(1), pp. 103-109.

14. Salimi Sahar, Nassiri Somayeh, Bayat Alireza. Lateral coefficient of friction for characterizing winter road conditions. Canadian journal of civil engineering, 2016, vol. 43(1), pp. 73-78.

15. Shoop S.A., Kestler M., Wieder W.L., MacDonald K. Lateral and Longitudinal Traction Measurements on Unpaved and Winter Road Surfaces. 18th International Conference of the International Society for Terrain Vehicle Systems 2014. Seoul, Korea, 2014, p. 64. 


\section{ДАННЫЕ ОБ АВТОРЕ}

Гергенов Сергей Митрофанович, старший научный сотрудник Управления научными исследованиями, доцент кафедры «Автомобили», кандидат технических наук

Восточно-Сибирский государственный университет технологий и управления

ул. Ключевская, 40В, г. Улан-Удэ, Республика Бурятия, 670013, Российская Федерация gergenovsm@gmail.com

\section{DATA ABOUT THE AUTHOR}

Sergey M. Gergenov, Senior Researcher of the Department of Scientific Research, Associate Professor of the Department of "Automobiles", Candidate of Technical Sciences

East Siberian State University of Technology and Management 40B, Klyuchevskaya Str., Ulan-Ude, Republic of Buryatia, 670013, Russian Federation

gergenovsm@gmail.com

ORCID: 0000-0001-6709-7810

ResearcherID: AAK-9370-2021

Scopus Author ID: 57212169497

Поступила 01.11 .2021

Received 01.11.2021

После рецензирования 15.11.2021

Revised 15.11.2021

Принята 02.12.2021

Accepted 02.12.2021 